\title{
HUMEDALES ARTIFICIALES Y CELDAS DE COMBUSTIBLES MICROBIANAS COMO SISTEMAS INDIVIDUALES Y COMBINADOS PARA EL TRATAMIENTO DE AGUAS RESIDUALES: UNA REVISIÓN
}

\author{
CONSTRUCTED WETLANDS AND MICROBIAL FUEL CELLS \\ AS INDIVIDUAL AND COMBINED SYSTEMS FOR WASTEWATER \\ TREATMENT: A REVIEW
}

\author{
Karla Montenegro-Rosero ${ }^{1,2}$, Lenys Fernández ${ }^{1,3}$, \\ Cristina Villamar-Ayala ${ }^{4}$ \& Patricio Espinoza-Montero ${ }^{1 *}$
}

Recibido: 30 de abril 2019 / Aceptado: 23 de mayo 2019

DOI: $10.26807 /$ ia.v7i2.100

Palabras clave: Aguas residuales; humedales artificiales; celda de combustible microbiana; sistemas combinados; bacterias electrógenas Keywords: Wastewater; constructed wetland; microbial fuel cell; combined systems; electrogenic bacteria

\section{RESUMEN}

El aumento poblacional y el desarrollo tecnológico ha ocasionado una gran demanda energética, lo que ha dado paso a que varios grupos de investigación incursionen en la búsqueda de soluciones a corto y mediano plazo. El uso de

1 Pontificia Universidad Católica del Ecuador, Escuela de Ciencias Químicas, Quito, Ecuador. (karlita.lucia95@gmail.com; Imfernandez@puce.edu.ec; *correspondencia: pespinoza646@puce.edu.ec)

2 Escuela Politécnica Nacional, Departamento de Ingeniería Civil y Ambiental, Quito, Ecuador. (karlita.lucia95@gmail.com)

3 Universidad Simón Bolívar, Departamento de Química, Caracas, Venezuela. (Ifernandez@usb.ve)

4 Universidad Santiago de Chile, Departamento de Ingeniería en Obras Civiles, Facultad de Ingeniería, Santiago, Chile. (cristina.villamar@usach.cl) 
tecnologías que permitan tratar aguas contaminadas y la generación simultánea de energía eléctrica surge como una alternativa viable para dar solución a este problema. En este documento se revisa el mecanismo para el tratamiento de agua residual y la generación de energía eléctrica simultánea, a través de sistemas combinados de humedales acoplados a celdas de combustible microbianas (CW-MFC, por sus siglas en inglés). El objetivo de esta revisión es describir los componentes y funcionamiento de los sistemas individuales $\mathrm{CW}$ y MFC, así como también del sistema combinado CW-MFC, los cuales han sido empleados en investigaciones recientes. Se exploran los principales estudios, relacionados con el material con el cual se construyen los electrodos, que generen mayor eficiencia energética y materiales filtrantes que beneficien el tratamiento del agua residual. Además, se presentan los desafíos en este ámbito de investigación. Los CW y las MFC son sistemas que combinados mejoran la eficiencia en el tratamiento de agua residual y a la vez permiten aprovechar la energía eléctrica que los microorganismos generan durante el proceso de oxidación de la materia orgánica.

\section{ABSTRACT}

The population increases and the technological development has caused a great energy demand, which has given way to several research groups venturing into the search for solutions in the short and medium term. The use of technologies to treat contaminated water and the generation of electrical energy simultaneously emerge as viable alternatives to solve the problem. This work reviews the mechanism for the treatment of wastewater and the generation of electrical energy simultaneously through combined systems of wetlands coupled to microbial fuel cells (CW-MFC). The objective of this review is to describe the components and operation of the individual CW and MFC systems, as well as the CW-MFC system, which have been used in recent research. The main studies were explored, studies related to the material that electrodes are built, which generate more energy efficiency and filtering materials that benefit the wastewater treatment. In addition, the challenges in this field of research are presented. The CW and the MFC are systems that, combined, improve the efficiency in the wastewater treatment and at the same time they allow to take advantage of the electrical energy that the microorganisms generate during the oxidation process of the organic matter. 


\section{INTRODUCCIÓN}

La acelerada contaminación del recurso hídrico en países en vías de desarrollo, causada principalmente por el incremento de las descargas de agua residual sin un previo tratamiento hacia efluentes naturales, representa un problema ambiental que hasta la actualidad no se ha logrado solucionar. A este problema se suma la falta de energía eléctrica. En la actualidad, han tomado fuerza tecnologías que permitan el tratamiento de agua residual y la generación de energía eléctrica de manera simultánea, (Ángeles et al., 2005). Las celdas de combustibles microbianas (MFC, por sus siglas en inglés), son un sistema bioelectroquímico que utiliza bacterias para degradar la materia orgánica y transformar energía química en energía eléctrica, (Logan et al., 2006). Por otra parte, los humedales artificiales (CW, por sus siglas en inglés), representan un tratamiento de aguas residuales no convencional de bajo costo. Sin embargo, al estudiarlos de forma individual no son tan eficientes como al combinarlos (Liu et al., 2004). En esta revisión se describen los componentes y funcionamiento de los sistemas individuales CW y MFC, así como también del sistema combinado CW-MFC, los cuales han sido empleados en investigaciones recientes.

\section{METODOLOGÍA}

\section{Humedales artificiales}

Los humedales artificiales son zonas diseñadas por el ser humano, con el fin de reproducir los procesos físicos químicos y biológicos que se dan en un humedal natural, pero en condiciones controladas, (Fallis, 2013). Esta tecnología ha sido estudiada como un tratamiento no convencional de agua residual, el cual a lo largo de los años ha tomado mayor importancia debido a su bajo costo y su alta eficiencia en la remoción de contaminantes, además, se reporta en la literatura estudios realizados con programas de modelación para optimizar las características de los 
CW (Fioreze \& Mancuso, 2019). El avance en la investigación de esta técnica se puede evidenciar, en el número de artículos publicados en revistas indexadas de acuerdo a la base de datos de Scopus, Figura 1.

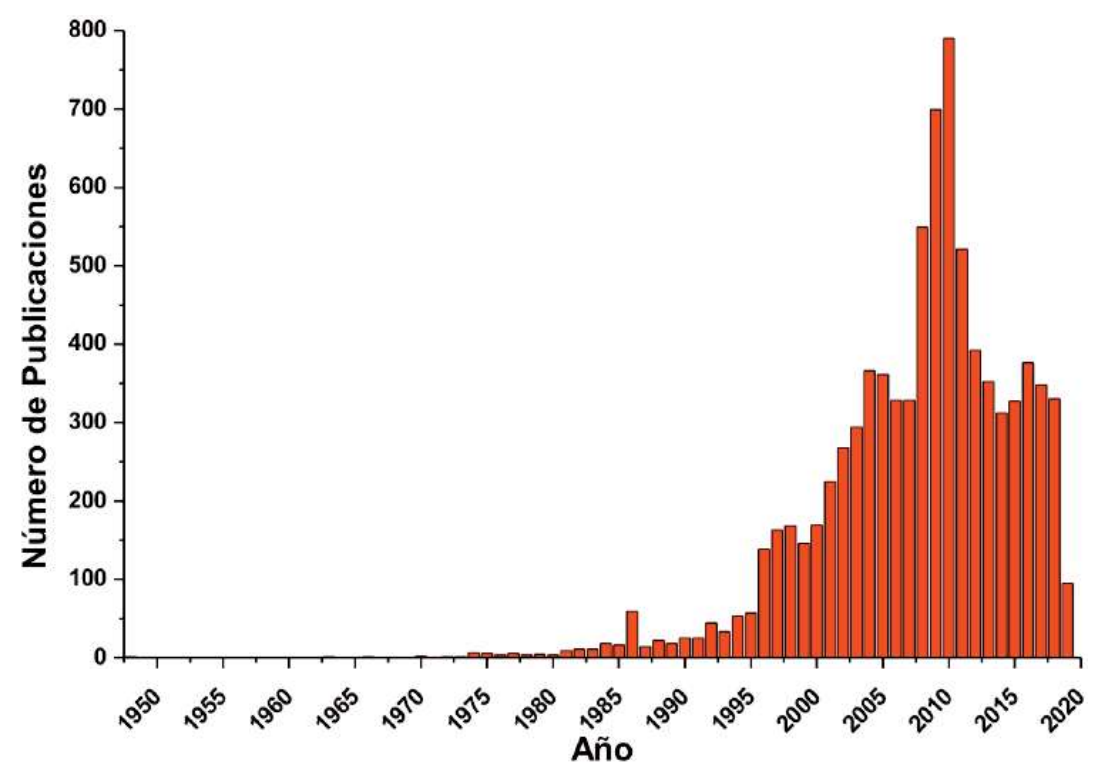

Figura 1. Número de publicaciones en el ámbito de humedales construidos desde 1948 hasta la actualidad, de acuerdo a la base de datos de Scopus

\section{Componentes de un CW}

Estos sistemas son considerados ecosistemas integrales y complejos debido a que en ellos interaccionan el sustrato, plantas, animales, microorganismos y el flujo de agua (Shi et al., 2018). Los CW están constituidos principalmente por: a) una capa impermeable que evita filtraciones y posible contaminación al suelo, b) el sustrato que da soporte a las macrófitas y a los microorganismos, c) la vegetación (macrófitas o plantas) y d) el influente (agua residual), Figura 2, (Fallis, 2013). 


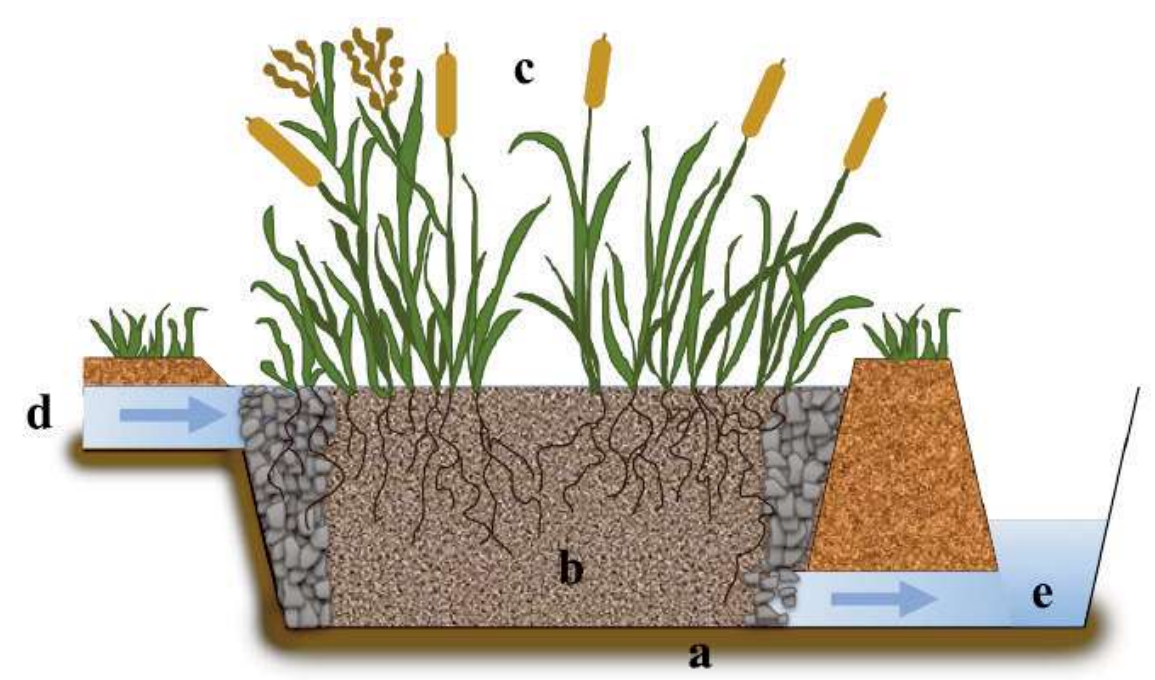

Figura 2. Componentes de un humedal artificial: a) capa impermeable, b) sustrato o lecho, c) vegetación (macrófitas), d) influente (agua residual), e) efluente (agua tratada)

Entre los materiales más utilizados para el lecho o sustrato están: tierra, arena, grava, roca, y materiales orgánicos tales como compost (Kadam et al., 2018; Saba et al., 2018). Las funciones principales que cumple el lecho son dar soporte a las plantas y a los microorganismos vivos; es el medio donde se realizan procesos de degradación de contaminantes, y además, la acumulación de materia orgánica brinda una fuente de carbono para los procesos químicos y biológicos (Edwards, 2000; USEPA, 1988).

La vegetación del CW consiste en plantas que pueden ser emergentes
(Typha latifolia), arraigadas flotantes (Ipomoea aquatic), sumergidas (Potamogeton perfoliatus) o flotantes (Eichornia Crassipes), Figura 3, la cuales ayudan a la estabilización del sustrato y el flujo de agua, oxigenan el medio, absorben carbono, nutrientes y elementos trazas, de tal forma que reducen la contaminación del agua, y sus raíces sirven para la fijación microbiana. Los microorganismos consisten en bacterias, levaduras, hongos, protozoos, algas (Jeppesen, 2012) y se encargan de la transformación de la materia orgánica e inorgánica en sustancias inocuas o insolubles (EPA, 1993; USEPA, 1988). 


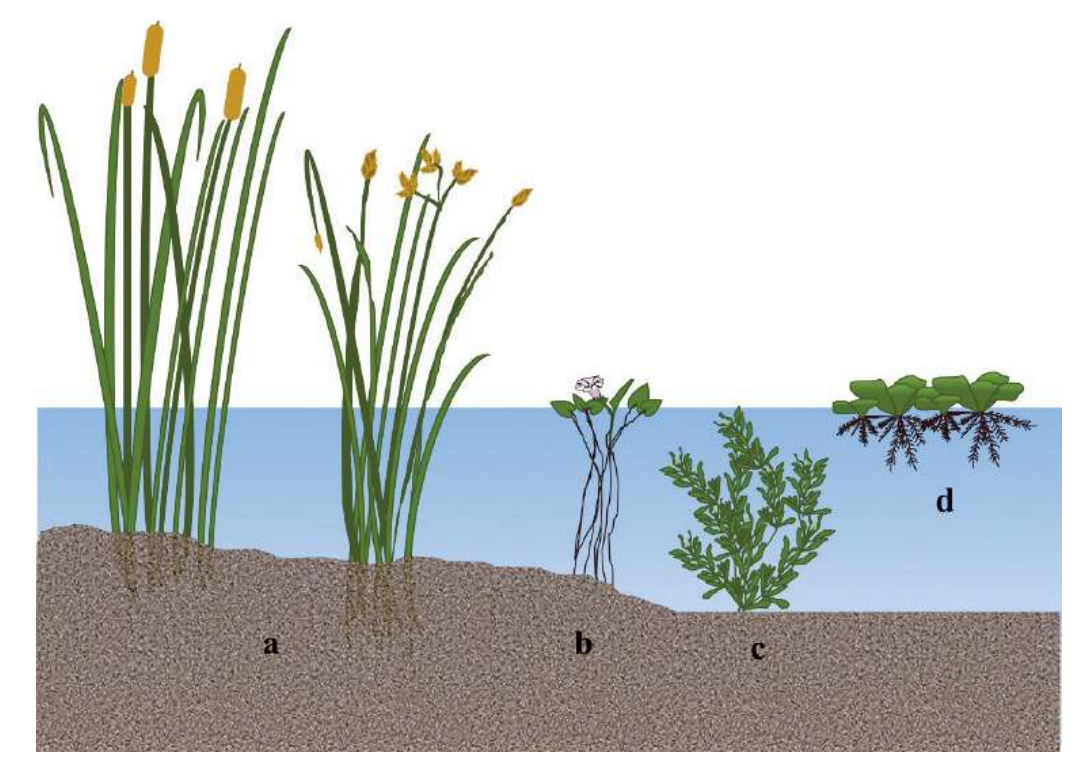

Figura 3. Tipos de macrófitas: a) emergentes, b) arraigadas flotantes, c) sumergidas, d) flotantes

Principio de funcionamiento y condiciones de diseño

En un humedal se dan procesos químicos, fiscos, biológicos y microbiológicos, a la vez que se desarrollan mecanismos de descontaminación del agua que incluyen adsorción, transformación y retención de contaminantes, filtración, reacciones redox de degradación, descomposición por agentes microbianos, acumulación de residuos, absorción y adsorción de nutrientes (Shi et al., 2018). Las consideraciones de diseño optimas de un $\mathrm{CW}$, dependen de factores como la ubicación geográfica, tipo de lecho y plantas, tipo de agua residual, clima, tiempo y la variabilidad estacionaria diaria (Edwards, 2000). Debido a que el diseño de un CW imita un humedal natural, debe tener un diseño sencillo y utilizar procesos naturales, como la influencia de la gravedad, integrarlo en la topografía del lugar, adicional a esto, es muy importante controlar la hidrología del sistema, el flujo debe ser lento, poco profundo y manejar sustratos saturados para proporcionar más tiempo de contacto entre el agua y el sustrato (Edwards, 2000; USEPA, 1988).

\section{Tipos de humedales}

Los humedales artificiales se clasifican de acuerdo al tipo y alimentación del flujo siendo así superficial o 
subsuperficial y horizontal o vertical respectivamente, Figura 4, (Edwards,
2000; Saba et al., 2018; Shi et al., 2018).

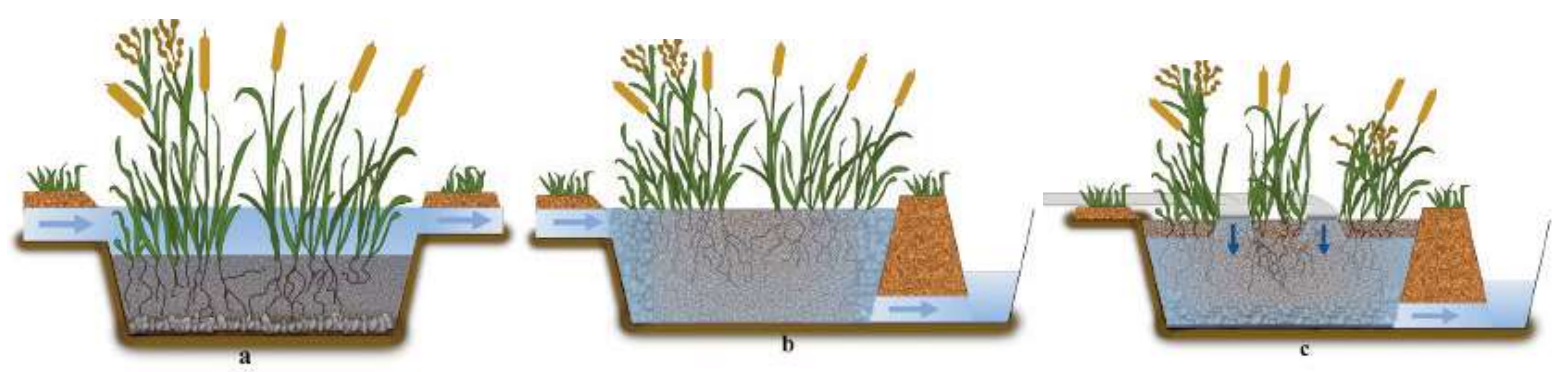

Figura 4. Tipos de humedales construidos: a) CW de flujo superficial, b) CW flujo horizontal subsuperficial, c) CW flujo vertical

\section{Celdas de combustible microbianas}

Las celdas de combustible microbianas (MFCs, por sus siglas en inglés) son dispositivos para el tratamiento de agua residual y la generación de energía eléctrica simultánea, esto se logra mediante el uso de microorganismos como biocatalizadores, los cuales oxidan la materia orgánica e inorgánica generando una gran cantidad de electrones, que al ser recolectados en un electrodo (ánodo) se convierten en energía eléctrica (Logan et al., 2006). Esta tecnología se ha venido desarrollando desde la década de los 70, donde se estudió a microorganismos catalizadores en celdas combustibles y en la década de los 90 se inician investigaciones para su aplicación en el tratamiento de agua residual domestica (Rabaey \& Verstraete, 2005). El estudio de este tipo de celdas ha crecido exponencialmente, Figura 5, debido al interés de generar energía eléctrica de una manera sustentable y dar solución a la contaminación de cuerpos de agua producto de las descargas de agua residual. 


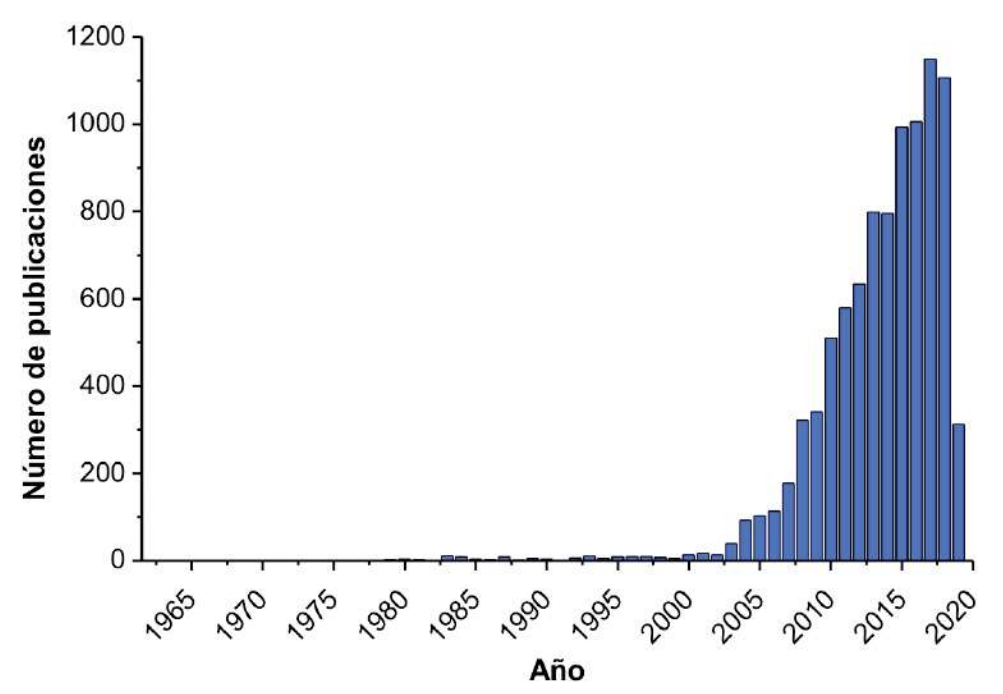

Figura 5. Número de publicaciones en el ámbito de celdas de combustible microbiana desde 1962 hasta la actualidad de acuerdo a la base de datos de Scopus

\section{Generalidades}

En una MFC las bacterias metabolizan la materia orgánica produciendo electrones, en un medio natural estos electrones generados son transferidos a un aceptor de electrones natural, como los nitratos o el oxígeno (Rabaey \& Verstraete, 2005), en un sistema electroquímico de una MFC, estos electrones se transfieren a un aceptor sólido externo (ánodo), el cual está conectado a un cátodo, mediante un circuito externo y una resistencia, Figura. 6. El movimiento de estos electrones produce una diferencia de potencial, y al Ilegar al cátodo en presencia del aceptor de electrones (oxígeno) forman agua (Logan et al., 2006; Y. Zhang et al., 2019).

\section{Componentes de una MFC}

Las celdas de combustible microbianas se componen de una membrana, una cámara anódica, y una cámara catódica, Figura 6. El diseño de las MFC varía dependiendo el tipo de membrana, electrodos, materiales de fabricación, entre otros. Los modelos más comunes para estas celdas son en forma de $\mathrm{H}$ (con dos cámaras separadas por una membrana) (Logan et al., 2006), una sola cámara (Liu et al., 2004), y modelos dependiendo el tipo de modificación específica que se realice en función del proceso y tipo de agua tratada (Zhang et al., 2019). 


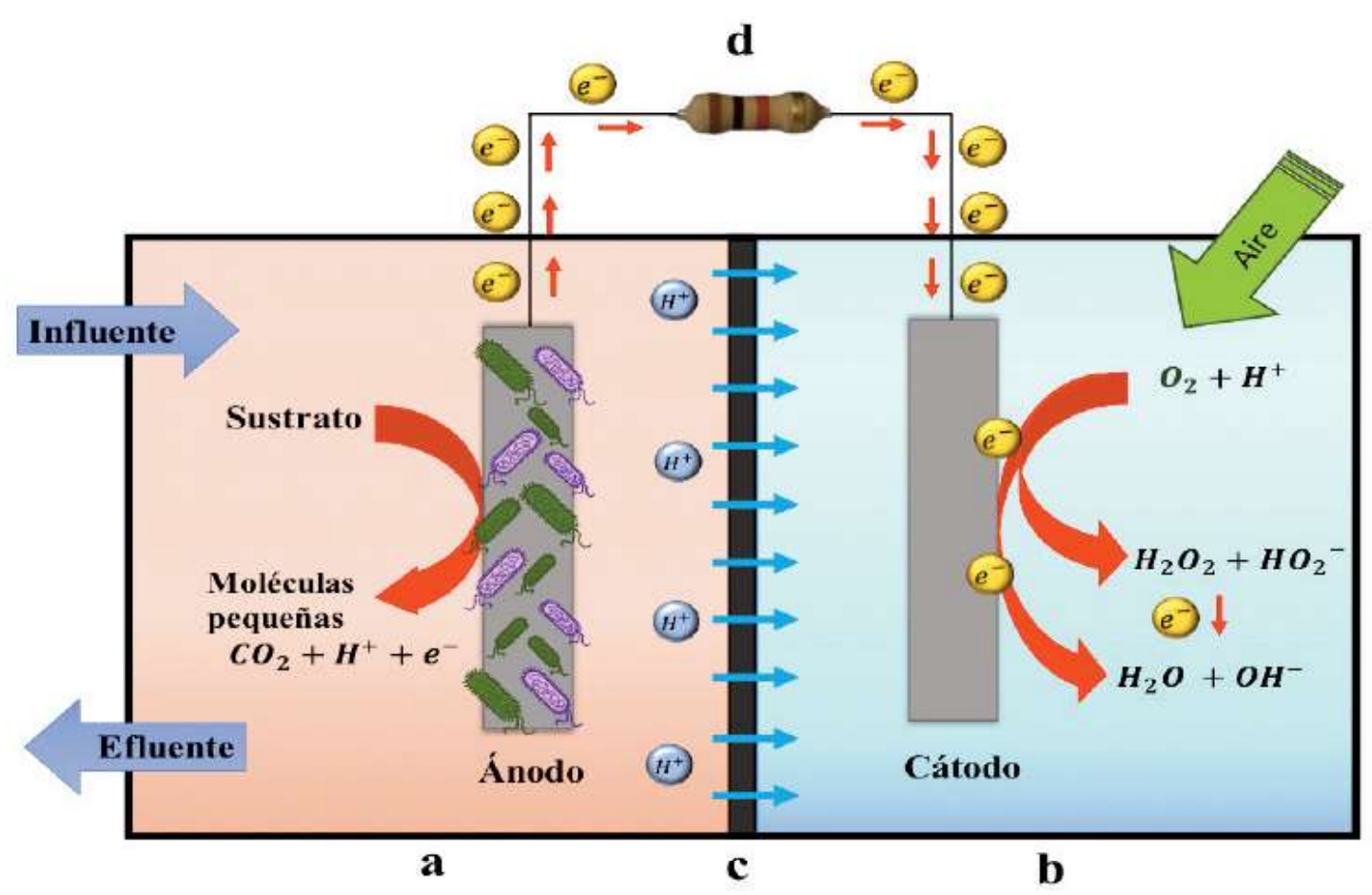

Figura 6. Estructura de una celda de combustible microbiano: a) cámara anódica, b) cámara catódica, c) membrana de intercambio catiónico, d) circuito externo

Membrana: la membrana de intercambio catiónico o membrana de intercambio protónico (PEM, por sus siglas en inglés) es fundamental en las MFC de dos compartimentos, ya que sirven para separar la cámara anódica de la cámara catiónica. Estas membranas son semipermeables, y permiten el paso de los protones $\left(\mathrm{H}^{+}\right)$ generados en el ánodo. Entre las PEM más estudiadas está el nafion, sin embargo, su uso es limitado debido a su alto costo (Gaurav et al., 2019). Según estudios realizados por Fasahat, (2017), se ha demostrados que en las MFC de una cámara, no es intrínsecamente necesario el uso de PEM ya que pueden disminuir el potencial eléctrico de la celda, además del alto costo económico que representa (Fasahat, 2017).

Cámara anódica: este compartimento actúa como un reactor anaeróbico, donde los microorganismos oxidan la materia orgánica presente en el agua residual, generando $\mathrm{CO}_{2}$, protones y electrones. Esta cámara está estructurada por un electrodo (ánodo) inoculado con bacterias bioelectrogénicas 
y por un sustrato (materia orgánica) presente en el agua residual. El ánodo debe tener alta conducción eléctrica (baja resistencia), alta porosidad (gran área superficial), debe ser resistente a la corrosión y a la obstrucción, fácil de instalar, bajo costo y tener un alto potencial de escalamiento (Fasahat, 2017). Para mejorar el rendimiento de la celda y no afectar negativamente a los microorganismos productores de electricidad, los mate- riales más comunes son: malla de acero inoxidable y carbono (placas, varillas y discos de grafito, fibras, esponja, fieltro, de carbono) (Logan et al., 2006).

Cámara catódica: a diferencia de la cámara anódica, este compartimento se encuentra en presencia de oxígeno debido a su gran poder oxidante (alta tendencia a reducirse) y su gran disponibilidad. El $\mathrm{O}_{2}$ actúa como aceptor de los electrones formados en el ánodo, y se reduce con los iones de $\mathrm{H}^{+}$formando agua (Logan et al., 2006). El material del cátodo afecta en el rendimiento de la producción de energía, por esta razón debe cumplir con las mismas características de ánodo. Adicional a esto, debe favorecer la reacción energéticamente, es decir, facilitar la reducción del oxígeno en la superficie, por esta razón los materiales más estudiados y modificados son: carbón, carbón vítreo (Ahn et al., 2017; Yin et al., 2019) y platino (Liu et al., 2019).

\section{Funcionamiento y condiciones de diseño}

Para degradar la materia orgánica las bacterias pueden seguir dos procesos metabólicos: la fermentación (cuando las bacterias no poseen aceptores de electrones en el medio) y la respiración celular que es la más común. A través del ciclo de Krebs la materia orgánica se va oxidando paulatinamente hasta obtener $\mathrm{CO}_{2}, \mathrm{H}_{2} \mathrm{O}$, ATP, $\mathrm{H}^{+}$y energía aprovechable (electrones libres), (Romero et al., 2012). Los electrones liberados en este proceso son recolectados por el ánodo y transferidos al cátodo mediante un circuito externo, los protones se desplazan hacia la cámara catiónica a través de la PEM para combinarse con el $\mathrm{O}_{2}$ y generar agua (Revelo \& Hurtado, 2013).

Los electrones son transferidos electroquímicamente desde las bacterias activas al ánodo, a través de tres me- 
canismos: a) estructuras propias del microorganismo como proteínas presentes en la membrana (pili-nanoconductores) (Malvankar \& Lovley, 2014), b) por contacto directo mediante los citocromos $\mathrm{C}$ y c) en el caso de bacterias no conductoras, mediadores endógenos o exógenos que se generan durante las reacciones redox de degradación de materia orgánica y su forma reducida es luego re-oxidada al transportar los electrones hacia el ánodo (Figura 7). Los mediadores deben tener facilidad de movimiento, alta solubilidad en el analito (Materia orgánica), alta velocidad de reacción con el ánodo, no deben afectar negativamente a los microorganismos y tener bajo costo, (Romero et al., 2012).

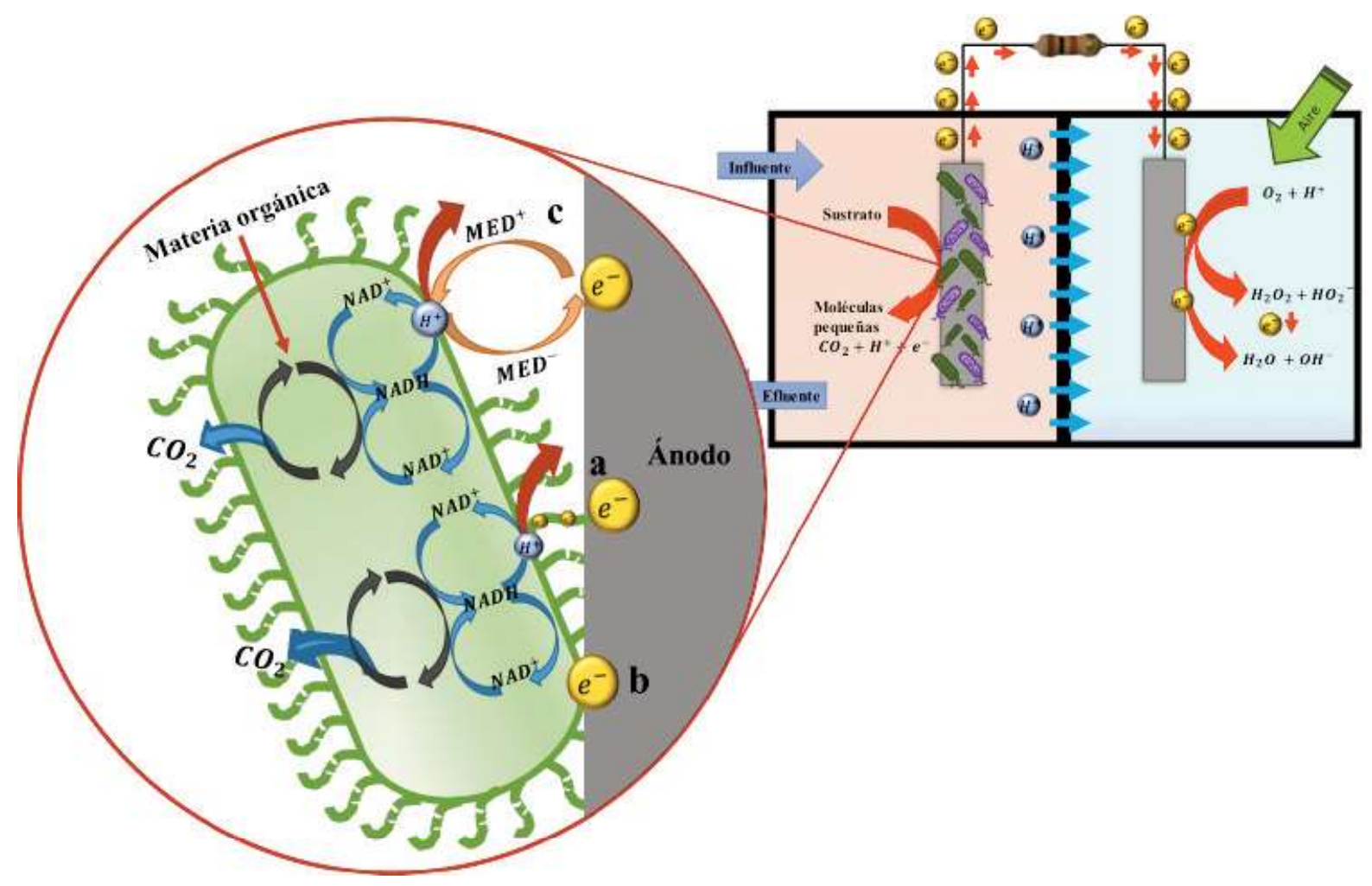

Figura 7. Proceso bioeletrogénico en una MFC y mecanismo de transferencia de electrones: a) estructuras propias del microorganismo (pili nanoconductores) b) por contacto directo mediante los citocromos C, y c) mediadores endógenos o exógenos

Para evaluar la eficiencia de las MFC se utilizan parámetros eléctricos cal- culados a partir del voltaje obtenido; como la densidad de potencia, que 
depende del área del electrodo, la resistencia interna (RI), la corriente eléctrica (I) y la eficiencia coulombica, que se define como la fracción de electrones recuperados frente a los electrones totales presentes en el sustrato, es decir es una relación entre la energía eléctrica obtenida y la degradación de la materia orgánica (disminución de la DQO), (Fang et al., 2013; Wu et al., 2014).

\section{Tipos de MFC}

Las MFC se han logrado combinar con procesos químicos, fiscos y biológicos, con el fin de mejorar la eficiencia en la producción de energía y el tratamiento del agua. En la tabla 1 se presenta un resumen de las principales técnicas combinadas con las MFC.

\section{Tabla 1. Celdas de combustible microbianas modificadas}

\begin{tabular}{|c|c|c|}
\hline Proceso & Sub proceso & Descripción \\
\hline \multirow{2}{*}{ Químicos } & Electro-fenton & $\begin{array}{l}\text { Producen radicales }\left({ }^{\circ} \mathrm{OH}\right) \text { altamente oxidativos y al ser com- } \\
\text { binados con una MFC aumentan su eficiencia en remoción } \\
\text { de ciertos contaminantes. }\end{array}$ \\
\hline & Fotoelectroquímico & $\begin{array}{l}\text { La celdas foto-electroquímicas aprovechan la energía solar } \\
\text { y la transforman en energía química, principalmente para } \\
\text { generar } \mathrm{H}_{2} \text { a partir de agua. }\end{array}$ \\
\hline \multirow{3}{*}{ Físicos } & $\begin{array}{l}\text { Desorción } \\
\text { Deionización } \\
\text { capacitiva }\end{array}$ & $\begin{array}{l}\text { (Electrosorción) se usa principalmente para la separación de } \\
\text { iones, aplicando un voltaje y creando una doble capa eléc- } \\
\text { trica, sus principales aplicaciones son la desalinización, sepa- } \\
\text { ración de metales y eliminación de contaminantes orgá- } \\
\text { nicos. }\end{array}$ \\
\hline & Membranas & $\begin{array}{l}\text { Una MFC se puede combinar con membranas dependiendo } \\
\text { el proceso específico como: ósmosis, ósmosis inversa, elec- } \\
\text { trodiálisis inversa, membranas bipolares y membranas de } \\
\text { utrafiltración. }\end{array}$ \\
\hline & $\begin{array}{l}\text { Biorreactores } \\
\text { de membrana }\end{array}$ & $\begin{array}{l}\text { Es una combinación de membranas de filtración con lodos } \\
\text { activados, mejorando la eficiencia en el tratamiento de } \\
\text { agua. }\end{array}$ \\
\hline & Electrólisis & $\begin{array}{l}\text { Los compuestos orgánicos son oxidados a } \mathrm{CO}_{2} \text { en la biope- } \\
\text { licula anódica a la vez que generan electrones que se tras- } \\
\text { ladan al cátodo para reducirse con protones }\left(\mathrm{H}^{+}\right) \text {y formar } \\
\mathrm{H}_{2} \mathrm{O}_{2} \text {. }\end{array}$ \\
\hline Biológicos & $\begin{array}{l}\text { MFC asistidas con } \\
\text { fotosíntesis }\end{array}$ & $\begin{array}{l}\text { Las MFC utilizan organismos fotosintetizadores como microal- } \\
\text { gas (algas-MFC), plantas (PMFC) y humedales artificiales } \\
\text { (CW-MFC), estas ocupan la energía solar para transformarla } \\
\text { en energía química y posteriormente en energía eléctrica. }\end{array}$ \\
\hline
\end{tabular}


Tratamientos convencionales
A diferencia de los sistemas híbridos anteriores, estos procesos funcionan de forma individual, proporcionando un pretratamiento y mejorar la eficiencia tanto en el tratamiento de agua y en la generación de energía.

Fuente: (Zhang et al., 2019)

\section{Sistemas combinados (CW-MFC)}

Los sistemas combinados de humedales artificiales acoplados a celdas de combustible microbianas son una tecnología nueva muy prometedora, debido a la combinación del tratamiento de agua residual y la generación de energía eléctrica de forma simultánea. Este sistema busca mejorar las deficiencias de los sistemas individuales (Srivastava et al., 2015). El $\mathrm{CW}$ es un proceso que requiere gran cantidad de terreno y un tiempo de retención alto, las MFC requieren ambientes anaerobios (para el ánodo) y aerobios (para el cátodo) y su escalamiento es complicado y costoso, al combinar estas dos tecnologías es posible subsanar limitaciones y mejorar la eficiencia de los procesos (Srivastava et al., 2015), es por esto que en los últimos años el interés en la investigación de esta tecnología ha ido creciendo, Figura 8.

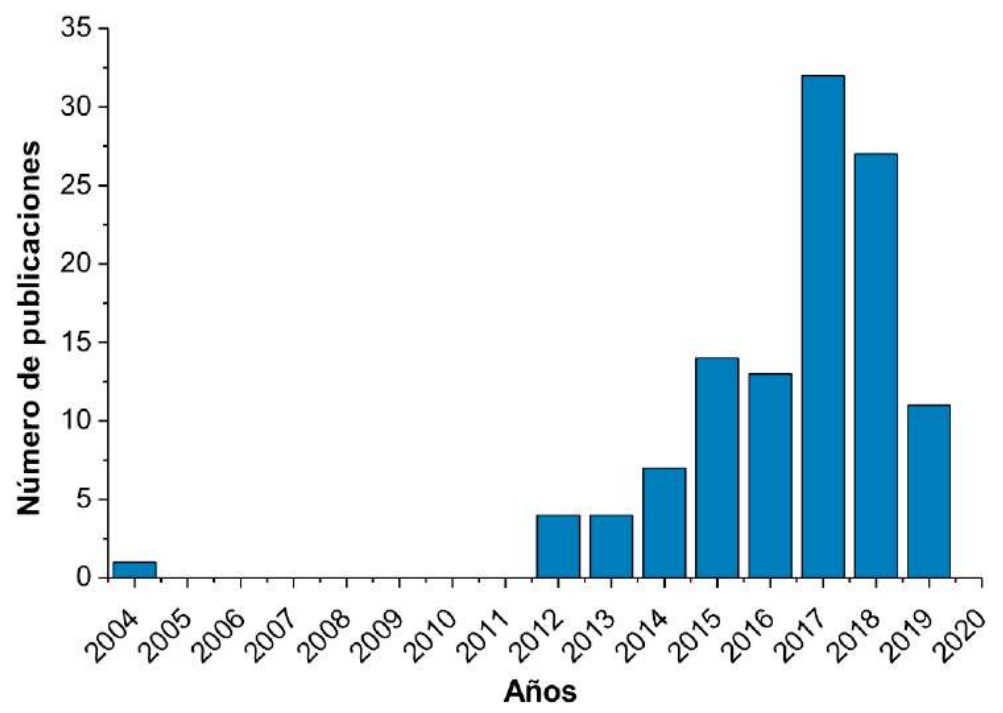

Figura 8. Número de publicaciones en el ámbito de sistemas combinados de Humedal construido acoplado a celdas de combustible microbiana desde 2004 hasta la actualidad de acuerdo a la base de datos de Scopus 
Los CW-MFC están constituidos por una zona anaerobia ubicada en el fondo del CW y en la cual funciona la cámara anódica de la MFC, y una zona aerobia ubicada en la risosfera y la superficie del CW, donde funciona la cámara catódica, además el lecho del humedal y las raíces de la planta brindan soporte para microorganismos electrogénicos (Yang, 2016). El ánodo y el cátodo están conectados entre sí mediante un circuito eléctrico externo (Figura 9), el cual sirve para monitorear la energía generada.

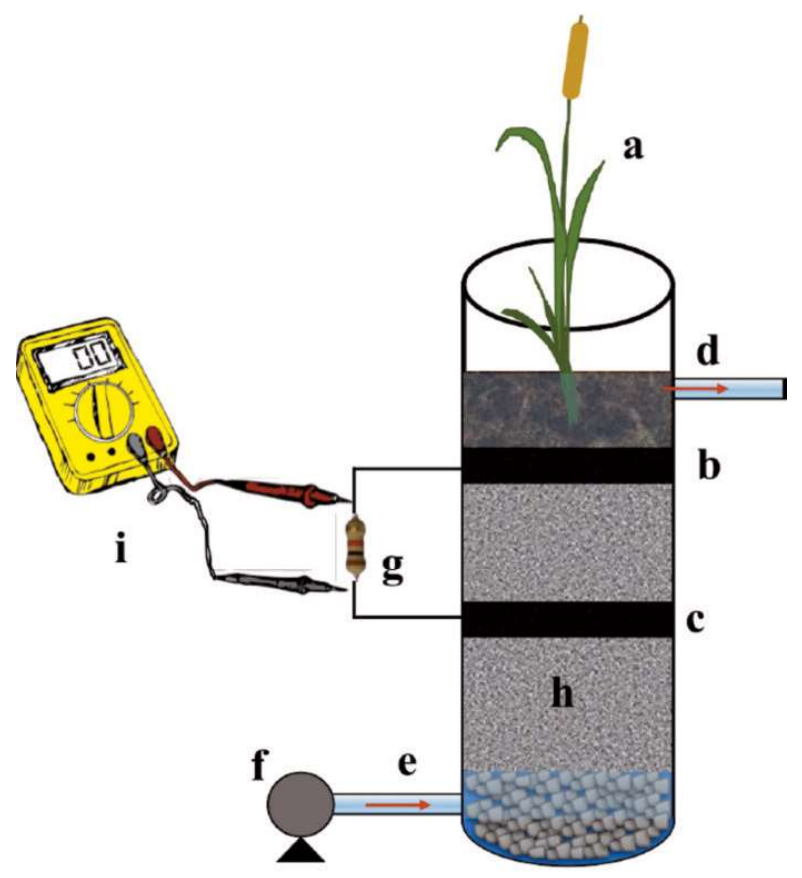

Figura 9. Estructura de un CW-MFC: a) macrófita, b) cátodo, c) ánodo, d) efluente, e) influente, f) bomba de agua, g) circuito externo (resistencia), h) medio de soporte o lecho, i) multímetro

\section{RESULTADOS}

En los últimos años se ha realizado varias investigaciones para optimizar este tipo de sistema, lo más estudiado es el material del ánodo y del cátodo, resistencia interna y externa, tipo de lecho y sustrato, contaminante específico y tipo de agua residual. Las investigaciones más relevantes se estudian en la Tabla 2. 
HUMEDALES ARTIFICIALES Y CELDAS DE COMBUSTIBLES MICROBIANASCOMO SISTEMAS

INDIVIDUALES Y COMBINADOS PARA EL TRATAMIENTO DE AGUAS RESIDUALES: UNA REVISIÓN

Montenegro et. al., 15-37

\section{Tabla 2. Principales estudios de los sistemas CW-MFC reportados en la literatura}

\begin{tabular}{|c|c|c|c|c|c|c|c|}
\hline \multirow{2}{*}{$\begin{array}{l}\text { Tipo de } \\
\text { sistema }\end{array}$} & \multicolumn{2}{|c|}{ Electrodo } & \multirow{2}{*}{ Planta } & \multirow{2}{*}{$\begin{array}{l}\text { Tipo de } \\
\text { agua } \\
\text { residual }\end{array}$} & \multirow{2}{*}{ Eficiencia } & \multirow{2}{*}{$\begin{array}{l}\text { Eficiencia } \\
\text { eléctrica }\end{array}$} & \multirow{2}{*}{ Referencia } \\
\hline & Ánodo & Cátodo & & & & & \\
\hline \multirow{2}{*}{ CW-MFC } & \multirow{2}{*}{$\begin{array}{l}\text { Malla de titanio } \\
\text { con carbón } \\
\text { activado }\end{array}$} & \multirow[b]{2}{*}{$\begin{array}{l}\text { Malla de } \\
\text { titanio }\end{array}$} & \multirow[b]{2}{*}{$\begin{array}{c}\text { Phragmites } \\
\text { australis }\end{array}$} & \multirow{2}{*}{$\begin{array}{l}\text { Agua } \\
\text { residual } \\
\text { sintética }\end{array}$} & \multirow{2}{*}{$\begin{array}{c}\mathrm{N}_{\mathrm{T}}=82,46 \pm \\
4,74 \% \\
\mathrm{DQO}=82,32 \pm \\
12,85 \% \\
\mathrm{P}_{\mathrm{T}}=95,06 \pm \\
5,45 \%)\end{array}$} & $\begin{array}{c}265,77 \pm \\
12,66 \mathrm{mV}\end{array}$ & \multirow{2}{*}{$\begin{array}{l}\text { (F. Xu et al., } \\
2018)\end{array}$} \\
\hline & & & & & & $\begin{array}{l}3714,08 \\
m W \cdot m^{12}\end{array}$ & \\
\hline $\begin{array}{l}\text { CW-MFC } \\
\text { Flujo } \\
\text { ascendente }\end{array}$ & Carbón activado & $\begin{array}{l}\text { Carbón } \\
\text { activado }\end{array}$ & $\begin{array}{l}\text { Elodea } \\
\text { nuttallii }\end{array}$ & $\begin{array}{l}\text { Agua } \\
\text { residual } \\
\text { sintética }\end{array}$ & $\begin{array}{l}\mathrm{NO}_{3}=50 \% \\
\mathrm{NH}_{4}=81 \%\end{array}$ & $\begin{array}{c}545,77 \pm 25 \\
\mathrm{mV} \\
184,75 \pm 7,50 \\
\mathrm{~mW} \mathrm{~m}^{3} \\
1,29 \mathrm{~W} \mathrm{~m}^{3}\end{array}$ & $\begin{array}{l}\text { (Y. L. Oon et } \\
\text { al., 2017) }\end{array}$ \\
\hline $\begin{array}{l}\text { CW-MFC } \\
\text { flujo vertical }\end{array}$ & Placas de grafito & $\begin{array}{c}\text { Placas de } \\
\text { grafito }\end{array}$ & $\begin{array}{l}\text { Juncus } \\
\text { effuses }\end{array}$ & $\begin{array}{l}\text { Agua } \\
\text { residual }\end{array}$ & $\begin{array}{c}\mathrm{N}_{\mathrm{T}}=69 \% \\
\mathrm{DQO}=69 \% \\
\mathrm{NH}_{4}{ }^{+} \mathrm{N}=92 \%\end{array}$ & $112 \mathrm{~mW} \mathrm{~m}^{-2}$ & $\begin{array}{c}\text { (Wu et al., } \\
2017 \text { ) }\end{array}$ \\
\hline CW-MFC & Grafito & $\begin{array}{l}\text { Placa de } \\
\text { magnesio }\end{array}$ & $\begin{array}{l}\text { Typha } \\
\text { latifolia }\end{array}$ & $\begin{array}{l}\text { Agua } \\
\text { residual } \\
\text { sintética }\end{array}$ & $\begin{array}{l}\mathrm{NO}_{3}=47,5 \% \\
\mathrm{NO}_{2}^{-}=19,1 \%\end{array}$ & $\begin{array}{l}78 \mathrm{~mW} \mathrm{~m}^{-2} \\
105 \mathrm{~mA} \mathrm{~m}^{-2}\end{array}$ & $\begin{array}{c}\text { (Can \& Yakar, } \\
2017)\end{array}$ \\
\hline CW-MFC & $\begin{array}{l}\text { Fieltro de } \\
\text { carbono }\end{array}$ & $\begin{array}{l}\text { Fieltro de } \\
\text { carbono }\end{array}$ & $\begin{array}{l}\text { Typha } \\
\text { latifolia }\end{array}$ & $\begin{array}{c}\text { Agua } \\
\text { sintética }\end{array}$ & $D Q O=95 \%$ & $8,67 \mathrm{~mW} \mathrm{~m}^{-2}$ & $\begin{array}{l}\text { (Y. Oon et al., } \\
2018)\end{array}$ \\
\hline $\begin{array}{l}\text { CW-MFC } \\
\text { biocátodos }\end{array}$ & $\begin{array}{l}\text { Grafito granular y } \\
\text { malla de acero } \\
\text { inoxidable } \\
\text { inoculado }\end{array}$ & $\begin{array}{l}\text { Fieltro de } \\
\text { carbono } \\
\text { inoculado }\end{array}$ & - & $\begin{array}{l}\text { Agua } \\
\text { esidual } \\
\text { sintética }\end{array}$ & - & $26,16 \mathrm{~mW} \mathrm{~m}^{-2}$ & $\begin{array}{l}\text { (L. Xuet al., } \\
2018 \text { ) }\end{array}$ \\
\hline CW-MFC & $\begin{array}{c}\text { Fieltro de carbono } \\
\text { (inoculados-lodos } \\
\text { de alumbre) }\end{array}$ & $\begin{array}{l}\text { Fieltro de } \\
\text { carbono }\end{array}$ & - & $\begin{array}{l}\text { Agua } \\
\text { esidual } \\
\text { sintética }\end{array}$ & - & $\begin{array}{c}465,7 \pm 4,2 \\
m V\end{array}$ & $\begin{array}{l}\text { (L. Xu et al., } \\
2018 \text { ) }\end{array}$ \\
\hline CW-MFC & $\begin{array}{c}\text { Grafito granular } \\
\text { Carbón activado } \\
\text { platino }\end{array}$ & $\begin{array}{l}\text { Grafito } \\
\text { granular } \\
\text { carbón } \\
\text { activado }\end{array}$ & $\begin{array}{l}\text { Canna } \\
\text { indica }\end{array}$ & $\begin{array}{l}\text { Agua } \\
\text { residual } \\
\text { sintética }\end{array}$ & - & $\begin{array}{l}66,22 \mathrm{~mW} \mathrm{~m}^{-2} \\
320,8 \mathrm{~mW} \mathrm{~m}^{-3} \\
422,2 \mathrm{~mA} \mathrm{~m}^{-3}\end{array}$ & $\begin{array}{l}\text { (Srivastava } \\
\text { et al., 2015) }\end{array}$ \\
\hline CW-MFC & Varillas de grafito & $\begin{array}{l}\text { Varillas de } \\
\text { grafito }\end{array}$ & $\begin{array}{l}\text { Phragmites } \\
\text { australiss }\end{array}$ & $\begin{array}{l}\text { Agua } \\
\text { residual } \\
\text { real }\end{array}$ & $\begin{array}{c}D Q O=61 \pm \\
19 \%\end{array}$ & $\begin{array}{c}80 \pm 56 \\
m W h \cdot m^{-2} \text { día } \\
131 \pm 61 \\
m W h m^{-2} \text { día }\end{array}$ & $\begin{array}{l}\text { (Corbella } \\
\text { et al., 2016) }\end{array}$ \\
\hline CW-MFC & Fibra de carbono & $\begin{array}{l}\text { Fibra de } \\
\text { carbono }\end{array}$ & $\begin{array}{l}\text { Canna } \\
\text { indica }\end{array}$ & $\begin{array}{l}\text { Agua } \\
\text { residual }\end{array}$ & $\begin{array}{c}\mathrm{DQO}=86,7 \% \\
\mathrm{NO}_{3}-\mathrm{N}=87,1 \%\end{array}$ & $8,91 \mathrm{~mW} \mathrm{~m}^{-2}$ & $\begin{array}{l}\text { (J. Wang et } \\
\text { al., 2017) }\end{array}$ \\
\hline CW-MFC & Carbón activado & $\begin{array}{l}\text { Carbón } \\
\text { activado } \\
\text { con malla de } \\
\text { acero inoxid. }\end{array}$ & $\begin{array}{l}\text { Ipomoea } \\
\text { aquatica }\end{array}$ & $\begin{array}{l}\text { Agua } \\
\text { residual } \\
\text { sintética }\end{array}$ & $D Q O=85,65 \%$ & $610 \mathrm{mV}$ & $\begin{array}{l}\text { (Fang et al., } \\
2013 \text { ) }\end{array}$ \\
\hline CW-MFC & Grafito & Grafito & $\begin{array}{c}\text { Phragmites } \\
\text { australis }\end{array}$ & $\begin{array}{l}\text { Agua } \\
\text { residual } \\
\text { sintética }\end{array}$ & - & $240 \mathrm{mV}$ & $\begin{array}{l}\text { (Camacho } \\
\text { et al., 2014) }\end{array}$ \\
\hline
\end{tabular}




\section{DISCUSIÓN}

Uno de los desafíos al que se enfrenta los sistemas CW-MFC, es la degradación de contaminantes emergentes específicos. En la literatura se reportan estudios para la degradación de: bisfenol A e ibuprofeno (Li et al., 2019), sulfodiazina (Wang et al., 2019a) colorantes azoicos: Acid Red 18 (AR18) (Fang et al., 2013; Oon et al., 2018), sulfametoxazol (Shen et al., 2018; Song et al., 2018; Zhang et al., 2017), nitrobenceno (Xie et al., 2018), boro (Can \& Yakar, 2017).

Debido a que esta tecnología es relativamente nueva, se sigue buscando optimizar las características a escala de laboratorio, por lo que, los reportes de condiciones multiparámetros o a escala real son escasos. La literatura re- porta estudios de la relación $\mathrm{DQO} / \mathrm{N}_{\mathrm{T}}$ siendo la más óptima $\mathrm{C} / \mathrm{N} \geq 3$ (Wang et al., 2019b). Además, un estudio multiparámetro que relaciona $(A)$ volumen de grafito granular, (B) OD en cátodo, (E) resistencia externa, (C) Tiempo de retención hidráulico, (D) recirculación del efluente, dando como parámetros más óptimos $A=20 \%$, $\mathrm{B}=1,5 \mathrm{mg} \mathrm{L}^{-1}, \mathrm{C}=1,5$ días, $\mathrm{D}=50 \%$, $E \leq 250 \Omega$ (Wang et al., 2019b). El estudio que le continua evalúa la relación de la producción de gases de efecto invernadero (Wang et al., 2019b). Además, existen escasos trabajos con parámetros reales, donde se destaca el trabajo de Harlt et al., (2019) con reactores a mesoescala utilizando agua residual doméstica real (Hartl et al., 2019).

\section{CONCLUSIONES}

Los CW son atractivos por su bajo costo, sencilla operación y versatilidad al tratar diferentes contaminantes, sin embargo, representan desafíos por su dimensionamiento, ya que requieren grandes extensiones de terreno. Las MFC son una tecnología relativamente nueva que tiene un atractivo interesante en la generación de energía eléctrica mediante el tratamiento de agua residual. Las investigaciones realizadas se enfocan principalmente en optimizar el diseño, encontrar el material de los electrodos adecuados, y en modificarlos con diversos procesos quími- 
HUMEDALES ARTIFICIALES Y CELDAS DE COMBUSTIBLES MICROBIANAS COMO SISTEMAS INDIVIDUALES Y COMBINADOS PARA EL TRATAMIENTO DE AGUAS RESIDUALES: UNA REVISIÓN

cos, físicos y biológicos, con el fin de aumentar el rendimiento eléctrico y mejorar el tratamiento del agua residual; sin embargo, el escalamiento genera altos costos y representa un problema para la implementación de este mecanismo. Cuando se combinan estas dos tecnologías, se logra tener una solución a las interferencias de los sistemas individuales, además, mejoran la eficiencia en el tratamiento de agua residual y a la vez permiten aprovechar la energía eléctrica que los microorganismos generan durante el proceso de oxidación de la materia orgánica, no obstante, esto solo ha abierto las puertas a las investigaciones para mejorar esta tecnología, siendo así los más estudiados el material, forma y números de electrodos, tipo de macrófita utilizada y tipos de lecho. Manteniendo como eje transversal en estos estudios a los microorganismos bioelectrogénicos.

\section{AGRADECIMIENTOS}

Al Laboratorio de Electroquímica de la Escuela de Ciencias Químicas de la Pontificia Universidad Católica del
Ecuador por apoyo brindado para esta investigación.

\section{LISTA DE REFERENCIAS}

Ahn, Y., Jo, S. Y., Song, Y. C., Lee, W., \& Chung, J. W. (2017). Application of Reticulated Vitreous Carbons doped with low-cost catalysts as the cathodes in microbial fuel cells. KSCE Journal of Civil Engineering, 21(3), 623-628. https://doi.org/10.1007 /s12205-016-1792-7

Ángeles, M. D. L., Patagónico, C. U., Rivadavia, C., \& Lladser, P. G. (2005). Crisis Energética Mundial. Colegio Universitario Patagónico, 1-5.

Camacho, J. V., Montano, C., Andrés, M., Rodrigo, R., Jesús, F., Morales, F., \& Cañizares, P. C. (2014). Energy production from wastewater using horizontal and vertical subsurface. Flow constructed wetlands, 13(10), 2523. 
Can, O., \& Yakar, A. (2017). A hybrid constructed wetland combined with microbial fuel cell for boron ( B ) removal and bioelectric production. Ecological Engineering, 102, 411-421. https://doi.org/10.1016/j.ecoleng.2017.02.034

Corbella, C., Garfí, M., \& Puigagut, J. (2016). Science of the Total Environment Longterm assessment of best cathode position to maximise microbial fuel cell performance in horizontal subsurface. Flow constructed wetlands, 564, 448-455. https://doi.org/10.1016/j.scitotenv.2016.03.170

Edwards, C. D. (2000). A handbook of constructed wetlands. Wetlands, 1, 53. Retrieved from http://citeseerx.ist.psu.edu/viewdoc/download?doi=10.1.1.169.7471\&amp; rep=rep 1 \&amp; type $=$ pdf

EPA. (1993). Subsurface flow constructed wetlands for wastewater treatment. A technology assessment. United States Environmental Protection Agency, 382. https://doi.org/10.1016/0925-8574(93)90009-5

Fallis, A. . (2013). Manual De Tecnologías No Convencionales Para La Depuración De Aguas Residuales. Journal of Chemical Information and Modeling (Vol. 53). https://doi.org/10.1017/CBO9781107415324.004

Fang, Z., Song, H., Cang, N., \& Li, X. (2013). Bioresource Technology Performance of microbial fuel cell coupled constructed wetland system for decolorization of azo dye and bioelectricity generation. Bioresource Technology, 144, 165-171. https://doi.org/10.1016/j.biortech.2013.06.073

Fasahat, S. (2017). Microbial Fuel Cells and Their Applications in Electricity Generating and Wastewater Treatment.

Fioreze, M., \& Mancuso, M. A. (2019). MODFLOW and MODPATH for hydrodynamic simulation of porous media in horizontal subsurface flow constructed wetlands: A tool for design criteria. Ecological Engineering, 130, 45-52. https://doi.org/10. 1016/j.ecoleng.2019.01.012

Gaurav, K., Singh, R., Tiwari, B. K., \& Srivastava, R. (2019). Novel proton exchange membranes based on PVC for microbial fuel cells (MFCs). Journal of Polymer Engineering, 39(4), 360-367. https://doi.org/10.1515/polyeng-2018-0276 
HUMEDALES ARTIFICIALES Y CELDAS DE COMBUSTIBLES MICROBIANAS COMO SISTEMAS INDIVIDUALES Y COMBINADOS PARA EL TRATAMIENTO DE AGUAS RESIDUALES: UNA REVISIÓN

Montenegro et. al., 15-37

Hartl, M., Bedoya-ríos, D. F., Fernández-gatell, M., Rousseau, D. P. L., Du, G., Garfí, M., \& Puigagut, J. (2019). Science of the Total Environment Contaminants removal and bacterial activity enhancement along the $\mathrm{fl}$ ow path of constructed wetland microbial fuel cells. Science of the Total Environment, 652, 1195-1208. https://doi.org/10.1016/j.scitotenv.2018.10.234

Kadam, S. K., Chandanshive, V. V., Rane, N. R., Patil, S. M., Gholave, A. R., Khandare, R. V., ... Govindwar, S. P. (2018). Phytobeds with Fimbristylis dichotoma and Ammannia baccifera for treatment of real textile effluent: An in situ treatment, anatomical studies and toxicity evaluation. Environmental Research, 160, 1-11. https://doi.org/10.1016/j.envres.2017.09.009

Li, H., Zhang, S., Yang, X., Yang, Y., Xu, H., \& Li, X. (2019). Chemosphere Enhanced degradation of bisphenol $\mathrm{A}$ and ibuprofen by an up- $\mathrm{fl}$ ow microbial fuel cell-coupled constructed wetland and analysis of bacterial community structure. Chemosphere, 217, 599-608. https://doi.org/10.1016/j.chemosphere.2018.11.022

Liu, H., Ramnarayanan, R., \& Logan, B. E. (2004). Production of Electricity during Wastewater Treatment Using a Single Chamber Microbial Fuel Cell. Environmental Science and Technology, 38(7), 2281-2285. https://doi.org/10.1021/es034923g

Liu, Y., Song, P., Gai, R., Yan, C., Jiao, Y., Yin, D., ... Zhang, L. (2019). Recovering platinum from wastewater by charring biofilm of microbial fuel cells (MFCs). Journal of Saudi Chemical Society, 23(3), 338-345. https://doi.org/10.1016/j.jscs.2018. 08.003

Logan, B. E., Hamelers, B., Rozendal, R., Schröder, U., Keller, J., Freguia, S., ... Rabaey, K. (2006). Microbial fuel cells: Methodology and technology. Environmental Science and Technology, 40(17), 5181-5192. https://doi.org/10.1021/es0605016

Malvankar, N. S., \& Lovley, D. R. (2014). Microbial nanowires for bioenergy applications. Current Opinion in Biotechnology, 27, 88-95. https://doi.org/10.1016/j.copbio. 2013.12.003 
Oon, Y. L., Ong, S. A., Ho, L. N., Wong, Y. S., Dahalan, F. A., Oon, Y. S., ... Nordin, N. (2017). Role of macrophyte and effect of supplementary aeration in up-flow constructed wetland-microbial fuel cell for simultaneous wastewater treatment and energy recovery. Bioresource Technology, 224, 265-275. https://doi.org/10.1016/ j.biortech.2016.10.079

Oon, Y., Ong, S., Ho, L., Wong, Y., Dahalan, F. A., Oon, Y., ... Nordin, N. (2018). Upflow constructed wetland-microbial fuel cell for azo dye, saline, nitrate remediation and bioelectricity generation: From waste to energy approach. Bioresource Technology, 266, 97-108, https://doi.org/10.1016/j.biortech.2018.06.035

Rabaey, K., \& Verstraete, W. (2005). Microbial fuel cells: Novel biotechnology for energy generation. Trends in Biotechnology, 23(6), 291-298. https://doi.org/10.1016/j. tibtech.2005.04.008

Revelo, D. M., \& Hurtado, N. H. (2013). Celdas de Combustible Microbianas ( CCMs ): Un Reto para la Remoción de Materia Orgánica y la Generación de Energía Eléctrica Microbial Fuel Cells ( MFCs ): A Challenge for the Removal of Organic Matter and Electricity Generation, 24(6), 17-28. https://doi.org/10.4067/S0718 07642 013000600004

Romero, A., Vásquez, J., \& González, A. (2012). Bacterias, fuente de energía para el futuro. Tecnura, 32, 118-143. https://doi.org/http://dx.doi.org/10.14483/udistrital. jour.tecnura.2012.2.a10

Saba, B., Khan, M., Christy, A. D., \& Veno, B. (2019). Microbial phyto-power systems A sustainable integration of phytoremediation and microbial fuel cells. 127, 1-11, Bioelectrochemistry,. https://doi.org/10.1016/j.bioelechem.2018.12.005

Shen, X., Zhang, J., Liu, D., Hu, Z., \& Liu, H. (2018). Enhance performance of microbial fuel cell coupled surface fl ow constructed wetland by using submerged plants and enclosed anodes. Chemical Engineering Journal, 351, 312-318. https://doi.org/10.1016/j.cej.2018.06.117

Shi, Y., Yang, X., Ning, X., \& Yang, Q. (2018). Research progress of microbial fuel cell and constructed wetland coupling system Research progress of microbial fuel cell and constructed wetland coupling system. IOP Conference Series: Earth and Environmental Science, 199, https://doi.org/10.1088/1755-1315/199/5/052014 
HUMEDALES ARTIFICIALES Y CELDAS DE COMBUSTIBLES MICROBIANAS COMO SISTEMAS INDIVIDUALES Y COMBINADOS PARA EL TRATAMIENTO DE AGUAS RESIDUALES: UNA REVISIÓN

Montenegro et. al., 15-37

Song, H., Li, H., Zhang, S., Yang, Y., Zhang, L., \& Xu, H. (2018). Fate of sulfadiazine and its corresponding resistance genes in up- $\mathrm{fl}$ ow microbial fuel cell coupled constructed wetlands : E ff ects of circuit operation mode and hydraulic retention time. Chemical Engineering Journal, 350, 920-929. https://doi.org/10.1016/ j.cej.2018.06.035

Srivastava, P., Yadav, A. K., \& Mishra, B. K. (2015). The effects of microbial fuel cell integration into constructed wetland on the performance of constructed wetland. Bioresource technology, 195, 223-230, https://doi.org/10.1016/j.biortech.2015. 05.072

USEPA. (1988). Design Manual: Constructed Wetlands and Aquatic Plant Systems for Municipal Wastewater Treatment, 92. https://doi.org/EPA/625/1-88/022

Wang, J., Song, X., Wang, Y., Bai, J., Bai, H., Yan, D., ... Dong, G. (2017). Bioresource Technology Bioelectricity generation, contaminant removal and bacterial community distribution as a ff ected by substrate material size and aquatic macrophyte in constructed wetland-microbial fuel cell. Bioresource Technology, 245, 372378. https://doi.org/10.1016/j.biortech.2017.08.191

Wang, X., Tian, Y., Liu, H., Zhao, X., \& Peng, S. (2019a). Science of the Total Environment Optimizing the performance of organics and nutrient removal in constructed wetland - microbial fuel cell systems. Science of the Total Environment, 653, 860871. https://doi.org/10.1016/j.scitotenv.2018.11.005

Wang, X., Tian, Y., Liu, H., Zhao, X., \& Peng, S. (2019b). Science of the Total Environment The in $\mathrm{fl}$ uence of incorporating microbial fuel cells on greenhouse gas emissions from constructed wetlands. Science of the Total Environment, 656, 270-279. https://doi.org/10.1016/j.scitotenv.2018.11.328

Wu, S., Kuschk, P., Brix, H., Vymazal, J., \& Dong, R. (2014). ScienceDirect Development of constructed wetlands in performance intensifications for wastewater treatment : A nitrogen and organic matter targeted review. Water Research, 57, 40-55. https://doi.org/10.1016/j.watres.2014.03.020 
Wu, S., Lv, T., Lu, Q., Ajmal, Z., \& Dong, R. (2017). Treatment of anaerobic digestate supernatant in microbial fuel cell coupled constructed wetlands: Evaluation of nitrogen removal, electricity generation, and bacterial community response. Science of the Total Environment, 580, 339-346. https://doi.org/10.1016/j.scitotenv. 2016.11.138

Xie, T., Jing, Z., Hu, J., Yuan, P., Liu, Y., \& Cao, S. (2018). Degradation of nitrobenzenecontaining wastewater by a microbial-fuel-cell- coupled constructed wetland. ECOlogical Engineering, 112, 65-71. https://doi.org/10.1016/j.ecoleng.2017.12.018

Xu, F., Cao, F., Kong, Q., Zhou, L., Yuan, Q., Zhu, Y., ... Wang, Z. (2018). Electricity production and evolution of microbial community in the constructed wetland-microbial fuel cell. Chemical Engineering Journal, 339, 479-486. https://doi.org/10. 1016/j.cej.2018.02.003

Xu, L., Zhao, Y., Tang, C., \& Doherty, L. (2018). In fl uence of glass wool as separator on bioelectricity generation in a constructed wetland-microbial fuel cell. Journal of Environmental Management, 207, 116-123. https://doi.org/10.1016/j.jevman. 2017.11.035

Xu, L., Zhao, Y., Wang, X., \& Yu, W. (2018). Applying multiple bio-cathodes in constructed wetland-microbial fuel cell for promoting energy production and bioelectrical derived nitri fi cation- denitri fi cation process. Chemical Engineering Journal, 344, 105-113. https://doi.org/10.1016/j.cej.2018.03.065

Yang, Q., Wu, Z., Liu, L., Zhang, F. \& Liang, S. (2016). Treatment of Oil Wastewater and Electricity Generation by Integrating Constructed Wetland with Microbial cell fuel. Materials, 9(11), 885. https://doi.org/10.3390/ma9110885

Yin, T., Zhang, H., Yang, G., \& Wang, L. (2019). Polyaniline composite TiO2 nanosheets modified carbon paper electrode as a high performance bioanode for microbial fuel cells. Synthetic Metals, 252, 8-14. https://doi.org/10.1016/j.synthmet. 2019.03.027

Zhang, S., Yang, X., Li, H., Song, H., Wang, R., \& Dai, Z. (2017). Bioresource Technology Degradation of sulfamethoxazole in bioelectrochemical system with power supplied by constructed wetland-coupled microbial fuel cells. Bioresource Technology, 244, 345-352. https://doi.org/10.1016/j.biortech.2017.07.143 
HUMEDALES ARTIFICIALES Y CELDAS DE COMBUSTIBLES MICROBIANAS COMO SISTEMAS INDIVIDUALES Y COMBINADOS PARA EL TRATAMIENTO DE AGUAS RESIDUALES: UNA REVISIÓN

Montenegro et. al., 15-37

Zhang, Y., Liu, M., Zhou, M., Yang, H., Liang, L., \& Gu, T. (2019). Microbial fuel cell hybrid systems for wastewater treatment and bioenergy production: Synergistic e ff ects, mechanisms and challenges. Renewable and Sustainable Energy Reviews, 103, 13-29. https://doi.org/10.1016/j.rser.2018.12.027 